\title{
Thermal Analysis of Cellulose Acetate Solids with Total Degrees of Substitution of 0.49, 1.75, 2.46, and 2.92
}

\author{
Kenji KAMIDE and Masatoshi SAITO \\ Textile Research Laboratory, Asahi Chemical Industry Co., Ltd., \\ 11-7 Hacchonawate, Takatsuki, Osaka 569, Japan
}

(Received October 26, 1984)

\begin{abstract}
The effects of the total degree of substitution $《 F\rangle$ and average-molecular weight on glass transition temperature $\left(T_{\mathrm{g}}\right)$, melting point $\left(T_{\mathrm{m}}\right)$ and the onset point of thermal decomposition $\left(T_{\mathrm{d}}\right)$ for cellulose acetate $(\mathrm{CA})$ solids were studied using DSC, TG, and X-ray diffractometry. Fractionated and whole CA polymers with $\langle\mathrm{F}\rangle$ of $0.49,1.75,2.46$, and 2.92 were used. All whole and fractionated CA showed $T_{\mathrm{g}} . T_{\mathrm{g}}$ of CA fractions do not depend on averagemolecular weight significantly, except for $\mathrm{CA}(2.92)$ (the number in parentheses denotes $\langle\mathrm{F}\rangle) . T_{\mathrm{g}}$ of $\mathrm{CA}$ fractions increases monotonously with a decrease in $\langle\mathrm{F}\rangle$ as follows

$$
\left.T_{\mathrm{g}}(\mathrm{K})=523-20.3 \ll \mathrm{F}\right\rangle
$$

To derive the above equation, the $T_{\mathrm{g}}$ value of a $\mathrm{CA}(2.92)$ fraction with a viscosity-average molecular weight of $1 \times 10^{5}$ was employed. $\langle\mathrm{F}\rangle$ dependence of $T_{\mathrm{g}}$ was considered related to the difference in the density of intermolecular interactions in CA solids. For CA(2.92) and some CA(2.46) fractions, cold crystallization occurs at a temperature about 30 and 20 degree higher than their $T_{\mathrm{g}}$, respectively. $T_{\mathrm{m}}$ and $T_{\mathrm{d}}$ of CA fractions were mainly determined by $\langle\mathrm{F}\rangle$, being independent of the average-molecular weight. $T_{\mathrm{m}}$ as well as $T_{\mathrm{d}}$ of CA(2.92) were highest among those of four kinds of CA, and CA(2.92) was thermally the most stable polymer among CA.

KEY WORDS Glass Transition Temperature / Crystallization Temperature /

Melting Point / Decomposition Temperature / Cellulose Acetate Solid /

DSC / TG / X-Ray Diffractometry /
\end{abstract}

Since Ueberreiter ${ }^{1}$ attempted to determine the second order transition temperature of cellulose diacetate and triacetate (CTA) by dilatometry, the thermal analysis of cellulose acetate (CA) solids has been energetically carried out using various methods, such as DSC, ${ }^{2-4}$ DTA, ${ }^{5,6}$ the dilatometry, ${ }^{9-15}$ and mechanical methods. ${ }^{12,13}$ However, the CA polymers used, except for those measured by Cowie and Ranson, ${ }^{2}$ were unfractionated and their average-molecular weights were not determined. Consequently, the molecular weight dependence of the glass transition temperature $\left(T_{\mathrm{g}}\right)$, the crystallization temperature $\left(T_{\mathrm{c}}\right)$, the melting point $\left(T_{\mathrm{m}}\right)$, and the onset of decomposition $\left(T_{\mathrm{d}}\right)$ have not yet been clarified. In addition, the dependence of $T_{\mathrm{g}}, T_{\mathrm{c}}, T_{\mathrm{m}}$, and $T_{\mathrm{d}}$ on the total degree of substitution $(\langle F\rangle)$ has not been reported since research work has been directed primarily to $\mathrm{CA}$, with a very limited range of $\langle\langle\mathrm{F}\rangle$, i.e., $\langle\mathrm{F}\rangle\rangle>2$. The relationship between thermal characteristic temperature and $\langle\mathrm{F}\rangle$ is of paramount importance to the molecular design of CA fibers with high thermal stability that would render them suitable as flameproofing materials. Recently, successive solution fractionation (SSF) has made it possible to prepare CA with relatively narrow molecular weight distribution $\left(M_{w} / M_{n}=\right.$ $1.2-1.5, M_{w}$, and $M_{n}$, the weight-average- and number-average molecular weights). ${ }^{16-19}$

In this article, we determined the $T_{\mathrm{g}}, T_{\mathrm{c}}, T_{\mathrm{m}}$, and $T_{\mathrm{d}}$ of fractionated and unfractionated CA having different $\langle\mathrm{F}\rangle$ using DSC, TG, and 
the X-ray diffraction method. The effects of $\langle\mathrm{F}\rangle$ and average-molecular weight on $T_{\mathrm{g}}, T_{\mathrm{m}}$, and $T_{\mathrm{d}}$ of CA are discussed.

\section{EXPERIMENTAL}

\section{(1) Sample Preparation}

CA whole polymers and fractions with four different $\langle\mathrm{F}\rangle$ values reported in previous papers, ${ }^{16-20}$ except some CA(2.92) fractions, were used. $\langle\langle\mathrm{F}\rangle$ and the average probability of substitution of the hydroxyl group attached to the $C_{k}(k=2,3,6)$ position in a pyranose ring and $\left\langle\mathrm{f}_{k}\right\rangle$ of whole polymers were determined by chemical analysis and ${ }^{1} \mathrm{H}$ and ${ }^{13} \mathrm{C}$ NMR, respectively. ${ }^{21}$ Table I lists the molecular char-

Table I. Molecular characterization of the cellulose acetate samples

\begin{tabular}{|c|c|c|c|c|c|}
\hline$\langle\mathrm{F}\rangle^{\mathbf{a}}$ & $\begin{array}{c}\text { Sample } \\
\text { No. }\end{array}$ & $\begin{array}{c}\text { Fraction or } \\
\text { whole polymer }\end{array}$ & $\begin{array}{r}\text { Molwt } \\
\times 10^{-4}\end{array}$ & $M_{w}^{\mathrm{b}} / M_{n}^{\mathrm{c}}$ & ref \\
\hline \multirow[t]{10}{*}{2.92} & TA3-1 & $\mathrm{F}^{\mathrm{d}}$ & $4.7\left(M_{v}^{\mathrm{e}}\right)$ & - & This work \\
\hline & TA3-2 & $\mathrm{F}$ & $12.6\left(M_{v}\right)$ & - & This work \\
\hline & TA2-7 & $\mathrm{F}$ & $14.9 \quad\left(M_{w}\right)$ & 1.30 & 16 \\
\hline & TA3-3 & $\mathrm{F}$ & $19.7\left(M_{v}\right)$ & - & This work \\
\hline & TA3-4 & $\mathrm{F}$ & $22.2\left(M_{v}\right)$ & - & This work \\
\hline & TA3-5 & $\mathrm{F}$ & $35.0 \quad\left(M_{v}\right)$ & - & This work \\
\hline & TA3-6 & $\mathrm{F}$ & $35.9 \quad\left(M_{v}\right)$ & - & This work \\
\hline & TA3-7 & $\mathrm{F}$ & $45.6\left(M_{v}\right)$ & - & This work \\
\hline & TA3-8 & $\mathrm{F}$ & $58.3\left(M_{v}\right)$ & - & This work \\
\hline & $\mathrm{TA} 2$ & $\mathrm{~W}^{\mathrm{f}}$ & $23.5 \quad\left(M_{w}\right)$ & - & 16 \\
\hline \multirow[t]{10}{*}{2.46} & EF3-4 & $\mathrm{F}$ & $5.3\left(M_{w}\right)$ & - & 17 \\
\hline & EF3-6 & $\mathrm{F}$ & $7.4 \quad\left(M_{w}\right)$ & 1.25 & 17 \\
\hline & EF3-8 & $\mathrm{F}$ & $10.0 \quad\left(M_{w}\right)$ & 1.31 & 17 \\
\hline & EF3-9 & $\mathrm{F}$ & - & - & 17 \\
\hline & EF3-10 & $\mathrm{F}$ & $10.8\left(M_{w}\right)$ & 1.26 & 17 \\
\hline & EF3-12 & $\mathrm{F}$ & $14.1 \quad\left(M_{w}\right)$ & 1.19 & 17 \\
\hline & EF3-13 & $\mathrm{F}$ & $15.6\left(M_{w}\right)$ & 1.26 & 17 \\
\hline & EF3-14 & $\mathrm{F}$ & $18.5 \quad\left(M_{w}\right)$ & 1.38 & 17 \\
\hline & EF3-15 & $\mathrm{F}$ & $26.5 \quad\left(M_{w}\right)$ & 1.30 & 17 \\
\hline & EF3 & W & $12.0 \quad\left(M_{w}\right)$ & - & 17 \\
\hline \multirow[t]{8}{*}{1.75} & KS2-1 & $\mathrm{F}$ & $2.1 \quad\left(M_{v}\right)$ & - & 20 \\
\hline & KS2-2 & $\mathrm{F}$ & $3.75\left(M_{w}\right)$ & 1.36 & 20 \\
\hline & KS2-4 & $\mathrm{F}$ & $5.53\left(M_{v}\right)$ & - & 20 \\
\hline & KS2-5 & $\mathrm{F}$ & $5.54\left(M_{w}\right)$ & - & 20 \\
\hline & KS2-7 & $\mathbf{F}$ & $7.72\left(M_{v}\right)$ & - & 20 \\
\hline & KS2-9 & $\mathrm{F}$ & $10.0\left(M_{w}\right)$ & 1.39 & 20 \\
\hline & KS2-10 & $\mathrm{F}$ & $13.1\left(M_{w}\right)$ & - & 20 \\
\hline & $\mathrm{KS} 2$ & $\mathrm{~W}$ & - & - & 20 \\
\hline \multirow[t]{7}{*}{0.49} & MA-3 & $\mathrm{F}$ & $4.55\left(M_{w}\right)$ & - & 18 \\
\hline & MA-6 & $\mathrm{F}$ & $6.76\left(M_{w}\right)$ & 1.30 & 18 \\
\hline & MA-8 & $\mathrm{F}$ & $7.94\left(M_{w}\right)$ & 1.31 & 18 \\
\hline & MA-10 & $\mathrm{F}$ & $10.8 \quad\left(M_{w}\right)$ & - & 18 \\
\hline & MA-11 & $\mathrm{F}$ & $11.1 \quad\left(M_{w}\right)$ & - & 18 \\
\hline & MA-13 & $\mathrm{F}$ & $14.5\left(M_{w}\right)$ & 1.28 & 18 \\
\hline & MA & W & - & - & 18 \\
\hline
\end{tabular}

a Total degree of substitution. ${ }^{\mathrm{b}}$ Weight-average molecular weight.

c Number-average molecular weight. ${ }^{d}$ Fraction.

e Viscosity-average molecular weight. ${ }^{\mathrm{f}}$ Whole polymer. 
acteristics of all the samples. CA(0.49) and $\mathrm{CA}(1.75)$ were synthesized by hydrolysis of the $\mathrm{CA}(2.46)$ whole polymer with $\mathrm{HCl}$ in an acetic acid solution. ${ }^{17,18}$ All CA fractions were prepared by the SSF method. For the fractionation of CA(2.92), a mixture of 1-chloro-2,3epoxypropane as a solvent and $n$-hexane as a precipitant was used, as proposed by Kamide et al. ${ }^{15}$ The viscosity-average molecular weight $M_{v}$ of the $\mathrm{CA}(2.92)$ fractions was estimated using the Mark-Houwink-Sakurada equation of the $\mathrm{CA}(2.92) / N, N$-dimethylacetamide (DMAc) system at $25^{\circ} \mathrm{C} .{ }^{16}$ Before measurement of DSC and TG, each sample was dryed at $1.3 \mathrm{~Pa}$ and $310 \mathrm{~K}$ for 2 days. The water content in the dried samples MA-14, EF3-12, TA2-7 was $0.98,0.81$, and $0.74 \pm$ $0.05 \%$, respectively.

\section{(2) DSC and TG Measurements}

DSC measurements were performed with a Perkin-Elmer Differential Scanning Calorimeter-type II, at a constant $\mathrm{N}_{2}$ flow-rate $\left(30 \mathrm{~cm}^{3}\right.$ $\mathrm{min}^{-1}$ ) and temperature ranging from 340 to $600 \mathrm{~K}$. TG was carried out on a Shimadzu TGA-30 M (Shimadzu, Kyoto) running $\mathrm{N}_{2}$ gas at a rate of $50 \mathrm{~cm}^{3} \mathrm{~min}^{-1}$. The heating rate $(\mathrm{HR})$ in the $\mathrm{DSC}$ and TG measurements was generally $10 \mathrm{~K} \mathrm{~min}^{-1}$.

\section{(3) X-Ray Diffraction}

Phase transition of the $\mathrm{CA}(2.92)$ fraction (TA3-4) and CA(2.46) fraction (EF3-14) in the temperature range of $293-577 \mathrm{~K}$ was examined by the X-ray diffractometer RU-200 PL (Rigaku Denki, Tokyo) equipped with a heating cell. ${ }^{22}$ Copper $K_{\alpha}$ radiation, monochromatized by Ni filter was used. The diffraction intensity was measured at $2 \theta=4-30^{\circ}$.

\section{RESULTS AND DISCUSSION}

\section{$C A(2.92)$}

The DSC curve of the CA(2.92) whole polymer and fractions is shown in Figure 1. In all samples, a baseline shift toward the

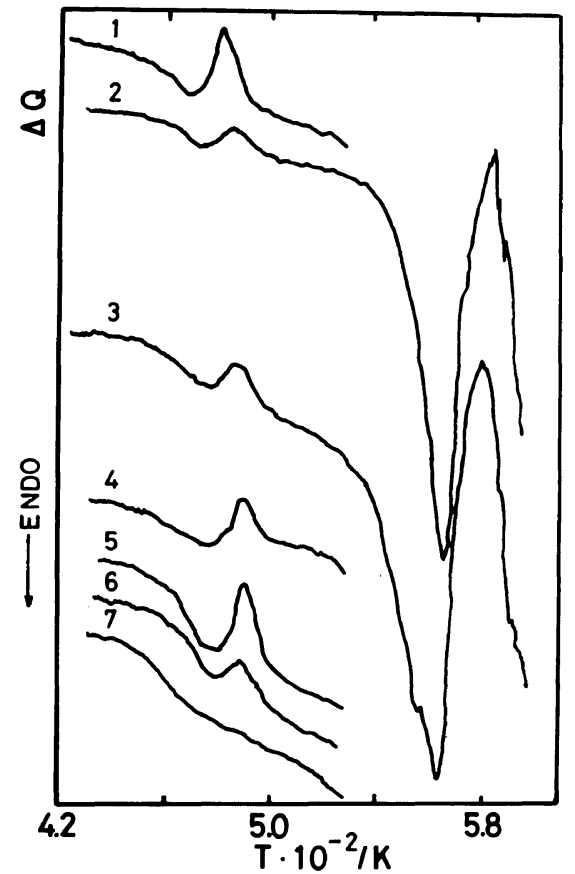

Figure 1. Differential scanning calorimetry (DSC) curves of $\mathrm{CA}(2.92)$ fractions $(1-6)$ and a whole polymer (7) at the heating rate $10 \mathrm{~K} \mathrm{~min}^{-1}$. 1, viscosityaverage molecular weight $M_{v}=4.7 \times 10^{4} ; 2, M_{v}=$ $1.97 \times 10^{5} ; 3, M_{v}=2.22 \times 10^{5} ; 4, M_{v}=3.59 \times 10^{5} ; 5, M_{v}=$ $4.56 \times 10^{5} ; 6, M_{v}=5.83 \times 10^{5} ; 7$, weight-average molecular weight $M_{w}=2.35 \times 10^{5}$.

endothermic side corresponding to the glass transition was observed between 440 and $480 \mathrm{~K}$. The inflection point in the baseline shift was defined as $T_{\mathrm{g}}$. In each DSC thermogram of the fractionated samples, an exothermic peak appeared at about $30 \mathrm{~K}$ higher than $T_{\mathrm{g}}$. The fractionated samples investigated here (sample TA3-3 with $M_{v}=1.97 \times 10^{5}$ and samples TA3-4 with $M_{v}=2.22 \times 10^{5}$ ) had very sharp endothermic peaks at 546 and $567 \mathrm{~K}$, respectively. The $T_{\mathrm{g}}$ of CA whole polymers with $\langle\mathrm{F}\rangle \geq 2.9$ determined by the DSC was reported to be $451-454 \mathrm{~K}\left(\mathrm{HR}=20 \mathrm{~K} \mathrm{~min}^{-1}\right)^{2}$ and these values are similar to the $T_{\mathrm{g}}$ of $\mathrm{CA}(2.92)$ whole polymers $(=460 \mathrm{~K})$ observed in this study.

Figure 2 shows the relation between $T_{\mathrm{g}}$ from DSC and $M_{v}$ for the CA(2.92) fractions. $T_{\mathrm{g}}$ increased with an increase in $M_{v}$ in the range 


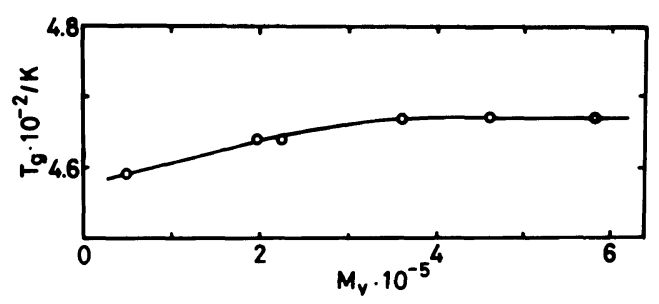

Figure 2. Glass transition temperature $T_{\mathrm{g}}$ of $\mathrm{CA}(2.92)$ fractions as a function of the viscosity-average molecular weight $M_{v}$.

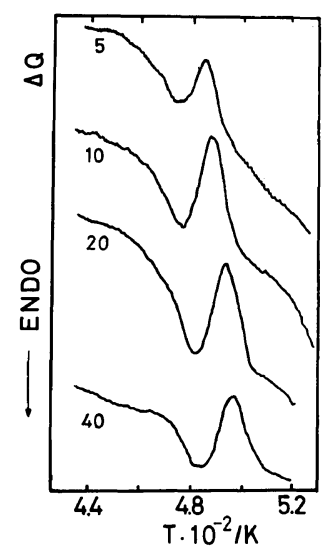

Figure 3. DSC curves of CA(2.92) fraction (TA3-4) with $M_{v}=2.22 \times 10^{5}$ at a heating rate from 5 to $40 \mathrm{~K} \mathrm{~min}^{-1}$. Number on each curve denotes heating rate.

of $M_{v} \leq 3.5 \times 10^{5}$ and became constant $(467 \mathrm{~K})$ at $M_{v} \geq 3.5 \times 10^{5}$ within experimental error. Similar molecular weight dependence of $T_{\mathrm{g}}$ was reported for cellulose tricarbanilate, amylose triacetate and amylose tripropionate. ${ }^{23}$

Figure 3 shows the effects of heating rate on the DSC curve of the sample TA3-4. In this case, $\mathrm{HR}$ varied from 5 to $40 \mathrm{~K}$ per min. $T_{\mathrm{g}}$ and the exothermic peak shifted to the higher temperature side at higher HR. Figure 4 depicts the DSC curves of fraction TA3-4 heated from room temperature to $510 \mathrm{~K}$ at a rate of $10 \mathrm{~K} \mathrm{~min}^{-1}$ (curve 1 in the figure) followed immediately by cooling to room temperature at the same $\mathrm{HR}$ as recorded in curve $1^{\prime}$. The exothermic peak at $483 \mathrm{~K}$ in the curve 1 disappeared in the course of cooling and never appeared again in subsequent cycles of heating and cooling. Curves $2-8$ denote the DSC

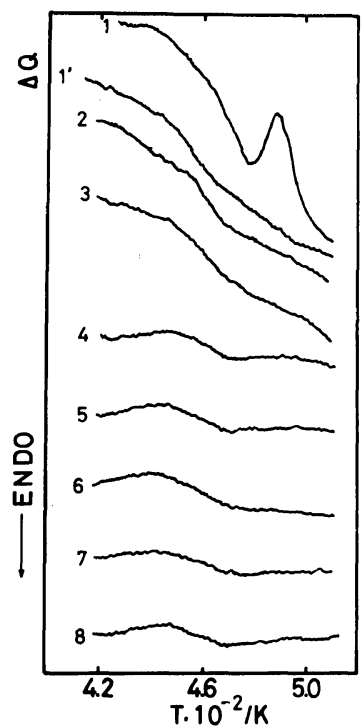

Figure 4. DSC curves of the $\mathrm{CA}(2.92)$ fraction (TA34) with $M_{v}=2.22 \times 10^{5}$ at a heating rate $10 \mathrm{~K} \mathrm{~min}^{-1} .1$, curves in heating process; $1^{\prime}$, cooling immediately after heating (curve 1 ); $2-8$, repeating order of cycle and curves during heating.

curves during heating at a given number of cycles.

The X-ray diffraction patterns of the fraction TA3-4 at five temperatures are shown in Figure 5. The diffractogram at $293 \mathrm{~K}$ has relatively sharp peaks at $2 \theta=7.1,8.4,17$, and $20.6^{\circ}$, indicating the crystal CTA II type ${ }^{24}$ structure. The diffractogram at $448 \mathrm{~K}$ was almost the same as that at $293 \mathrm{~K}$. At 498 and $517 \mathrm{~K}$ the intensity at $2 \theta=8.4,10.0$, and $12.2^{\circ}$ increased and two new peaks appeared at $2 \theta=$ 15.8 and $17.8^{\circ}$. We evaluated the diffraction intensity, a measure of crystallinity, from the area under the peaks of the diffractogram between $2 \theta=5$ and $30^{\circ}$. Here the X-ray diffractograms in the figure were redrawn with smooth lines to eliminate the noise and the baseline was conventionally drawn to pass through the point at $2 \theta=5$ and $14^{\circ}$ and $2 \theta=14$ and $30^{\circ}$. Figure 6 shows the relation between the ratio of diffraction intensity at various temperatures to that at $293 \mathrm{~K}$ (we denote this ratio as DIR) and the temperature for 


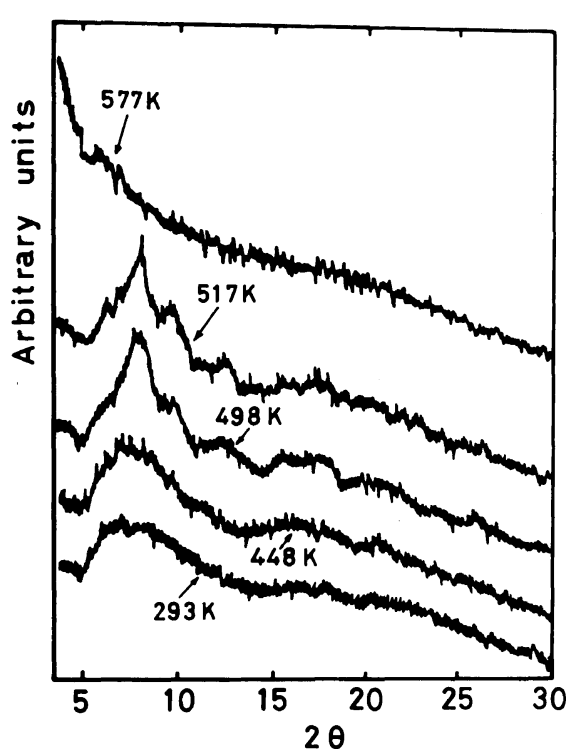

Figure 5. X-Ray diffractograms of the $\mathrm{CA}(2.92)$ fraction (TA3-4) at temperatures from 293 to $577 \mathrm{~K}, 2 \theta$, diffraction angle. Number to each curve denotes temperature.

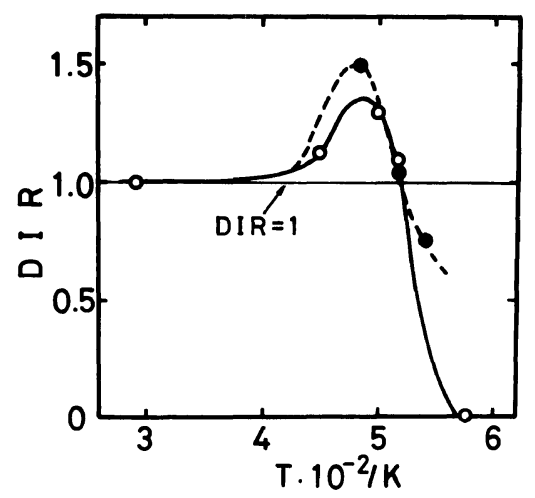

Figure 6. Relation between diffraction intensity ratio (DIR) estimated from the X-ray diffractograms of $\mathrm{CA}(2.92)$ and $\mathrm{CA}(2.46)$ and temperature. - $\mathrm{O}-$, $\mathrm{CA}(2.92)$ fraction, ------, $\mathrm{CA}(2.46)$ fraction.

CA(2.92) (solid line). DIR of CA(2.92) fraction at $498 \mathrm{~K}$ was about $30 \%$ higher than that at $293 \mathrm{~K}$ and reached a maximum near $490 \mathrm{~K}$. The increase in X-ray diffraction intensity of the CTA solid with annealing was also reported by Sprague et $a l^{25}$ and Creely and Conrad. ${ }^{26}$ These results indicate the exothermic peak at $478 \mathrm{~K}$ in DSC curve of the fraction TA3-4 is caused by crystallization. The temperature of crystallization of CA(2.92) was about 30 degree higher than $T_{\mathrm{g}}$, corresponding to the so-called "cold crystallization" first observed for undrawn poly(ethylene terephthalate) fibers. ${ }^{27}$ Above about $490 \mathrm{~K}$, the crystallinity decreased monotonously and in the diffractogram at $577 \mathrm{~K}$, all peaks disappeared and only an amorphous hallow remained. We may thus conclude the endothermic peak of DSC at about $564 \mathrm{~K}$ to be $T_{\mathrm{m}}$. This $T_{\mathrm{m}}$ value is very close to those of two fractions (fraction code $\mathrm{W} .366(\langle\mathrm{~F}\rangle)=2.86$, $\left.M_{n}=1.63 \times 10^{5}\right)$ and $\mathrm{W} .325\left(\langle\mathrm{~F}\rangle=2.88, M_{n}=\right.$ $\left.\left.5.3 \times 10^{4}\right)\right)(566$ and $576 \mathrm{~K}$, respectively) measured by Cowie and Ranson ${ }^{2}$ using DSC at $\mathrm{HR}=20 \mathrm{~K} \mathrm{~min}^{-1}$. Patel et al. $^{6}$ regarded the endothermic peaks at 543 and $533 \mathrm{~K}$ in the DTA curves $\left(\mathrm{HR}=10 \mathrm{~K} \mathrm{~min}^{-1}\right)$ of $\mathrm{CA}(3.0)$ and $\mathrm{CA}(2.94)$ whole polymer films as $T_{\mathrm{m}}$. These are about $25-35 \mathrm{~K}$ lower than those from our results. The CA films used by Patel et al. were prepared by evaporating the solvent $\left(\mathrm{CHCl}_{3}\right)$ from the solution. There is a possibility that the crystallinity and the perfectness of the crystals of their sample are lower than those in this study.

\section{$C A(2.46), C A(1.75)$, and $C A(0.49)$}

Figures $7-9$ show the DSC curves of some fractions and whole polymers of CA(2.46), CA(1.75), and CA(0.49). The DSC curves of the $\mathrm{CA}(2.46)$ fractions have the baseline shift to the endothermic side in the range of $450-480 \mathrm{~K}$ due to the glass transition. However, in the case of the whole polymers, no remarkable shift in the DSC curve was detected. The fractions with $M_{w}=$ $1.08 \times 10^{5}$ and $1.85 \times 10^{5}$ have a small exothermic peak at a temperature about $20 \mathrm{~K}$ higher than $T_{\mathrm{g}}$. All of the samples of CA(2.46) have the sharp endothermic peak in the range $500-510 \mathrm{~K}$, and the fractions with $M_{w} \geq 1.41 \times 10^{5}$ have another endothermic peak (in the case of $M_{w}=1.08 \times 10^{5}$ and $1.41 \times$ $10^{5}$, a shoulder) at about $520 \mathrm{~K}$. 


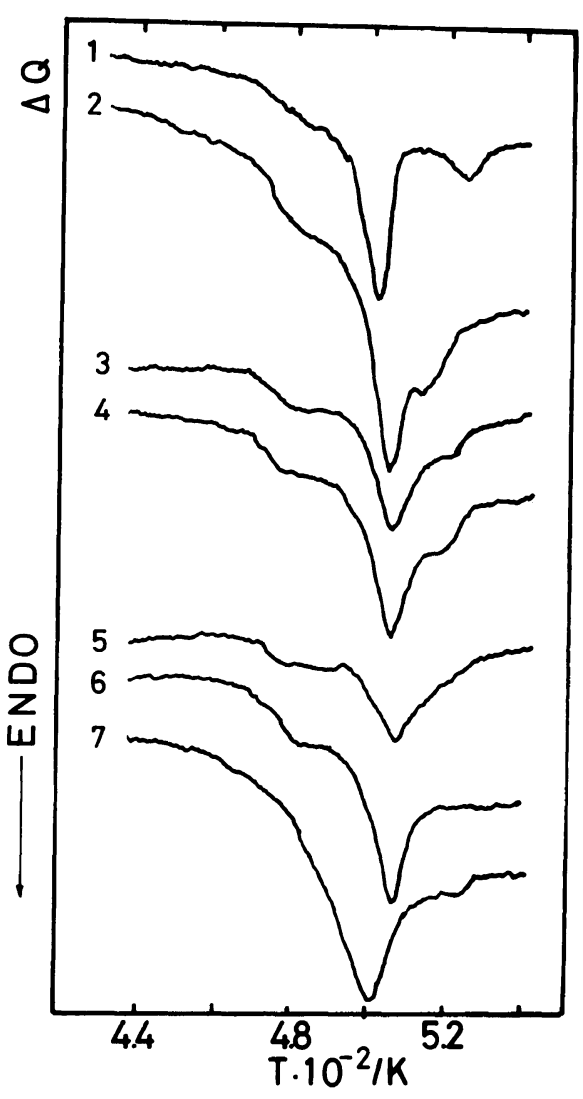

Figure 7. DSC curves of the $\mathrm{CA}(2.46)$ fractions (1-6) and a whole polymer (7) at a heating rate of $10 \mathrm{~K} / \mathrm{min} .1, M_{w}=5.3 \times 10^{4} ; 2, M_{w}=7.4 \times 10^{4} ; 3, M_{w}=$ $1.08 \times 10^{5} ; 4, \quad M_{w}=1.41 \times 10^{5} ; 5, M_{w}=1.85 \times 10^{5} ; 6$, $M_{w}=2.65 \times 10^{5} ; 7, M_{w}=1.2 \times 10^{5}$.

The DSC curves of the CA(1.75) fractions and whole polymers also have $T_{\mathrm{g}}$ in the temperature range from 480 to $500 \mathrm{~K}$ and an endothermic peak at about $510 \mathrm{~K}$. The $\mathrm{CA}(0.49)$ fractions and their whole polymers have $T_{\mathrm{g}}$ at $500-530 \mathrm{~K}$, but no endothermic peak at about $500-510 \mathrm{~K}$, which appeared for the $\mathrm{CA}(2.46)$ and $\mathrm{CA}(1.75)$ polymers, was detected.

$T_{\mathrm{g}}$ of $\mathrm{CA}$ with $\langle\mathrm{F}\rangle$ from 2.2 to 2.8 reported in literature scattered a little, depending on the measuring method. For example, $T_{\mathrm{g}}$ of the $\mathrm{CA}(2.47)$ whole polymer was reported at $491 \mathrm{~K}$ by $\mathrm{DSC},{ }^{5}$ and that of the CA whole polymer with $\langle\mathrm{F}\rangle$ from 2.23 to 2.75 at 453 -

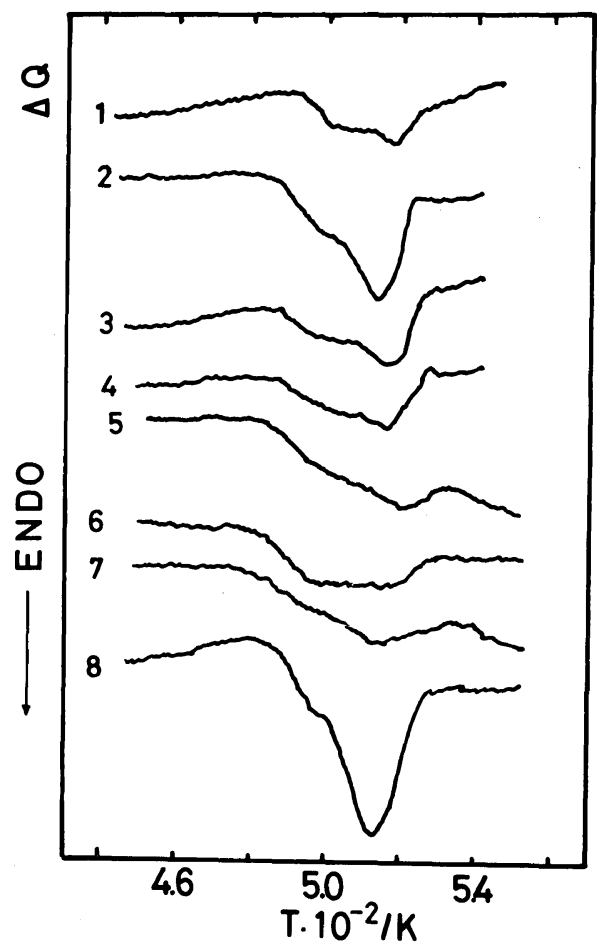

Figure 8. DSC curves of the CA(1.75) fractions $(1-7)$ and a whole polymer $(8)$ at a heating rate of $10 \mathrm{~K} \mathrm{~min}^{-1} .1, M_{v}=2.1 \times 10^{4} ; 2, M_{w}=3.75 \times 10^{4} ; 3$, $M_{v}=5.53 \times 10^{4} ; 4, M_{w}=5.54 \times 10^{4} ; 5, M_{v}=7.72 \times 10^{4} ; 6$, $M_{w}=1.00 \times 10^{5} ; 7, M_{w}=1.31 \times 10^{5}$.

$476 \mathrm{~K}$ by mechanical methods. ${ }^{12,13}$ By dilatometry, a second order transition was observed at three temperature ranges, $288,{ }^{15}$ $310-340,{ }^{11-13,15}$ and $360-390 \mathrm{~K}^{11-13,15}$. Unfortunately no experiment using dilatometry could be carried out at a temperature higher than $450 \mathrm{~K}$, at which $T_{\mathrm{g}}$ was reported by the previous two methods.

DSC and DTA data in the literature on CA with $\langle\bar{F}\rangle$ smaller than 2 are very few. Patel $e t$ $a l .{ }^{6}$ carried out DTA analysis on CA(1.60) and $\mathrm{CA}(0.9)$ whole polymers, but failed to detect the $T_{\mathrm{g}}$ of these polymers.

Figure 10 shows the relation between $T_{\mathrm{g}}$ of $\mathrm{CA}(2.46), \mathrm{CA}(1.75)$, and $\mathrm{CA}(0.49)$ fractions and their molecular weights. $T_{\mathrm{g}}$ of CA polymer was mainly determined by $\langle\mathrm{F}\rangle$ and was independent of the average-molecular weight. 


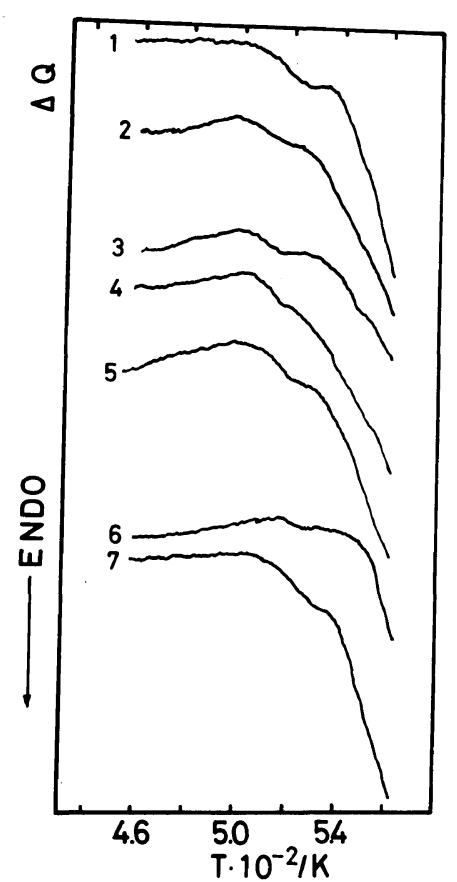

Figure 9. DSC curves of the $\mathrm{CA}(0.49)$ fractions (1-6) and a whole polymer (7) at a heating rate of $10 \mathrm{~K} \mathrm{~min}^{-1} .1, M_{w}=4.55 \times 10^{4} ; 2, M_{w}=6.76 \times 10^{4} ; 3$, $M_{w}=7.94 \times 10^{4} ; 4, M_{w}=1.08 \times 10^{5} ; 5, M_{w}=1.11 \times 10^{5}$; $6, M_{w}=1.45 \times 10^{5}$.

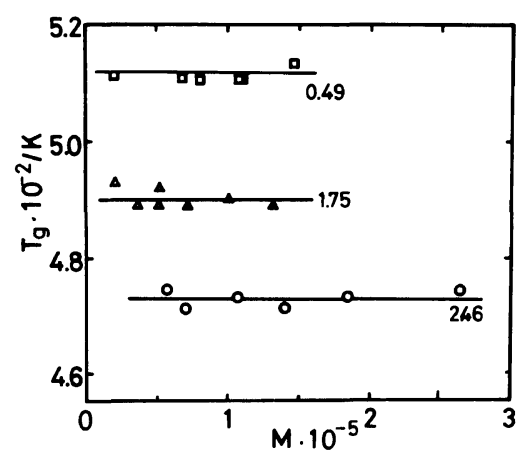

Figure 10. $T_{\mathrm{g}}$ of $\mathrm{CA}(2.46), \mathrm{CA}(1.75)$ and $\mathrm{CA}(0.49)$ fractions determined by DSC as a function of molecular weight. $\bigcirc, \mathrm{CA}(2.46) ; \triangle, \mathrm{CA}(1.75) ; \square, \mathrm{CA}(0.49)$. Numbers on the lines denote total degrees of substitution.

Averaged $T_{\mathrm{g}}$ values of $\mathrm{CA}(2.46), \mathrm{CA}(1.75)$, and $\mathrm{CA}(0.49)$ were $472.5,489.5$, and $511.5 \mathrm{~K}$, respectively.

Figure 11 shows the $\mathrm{X}$-ray diffractograms of

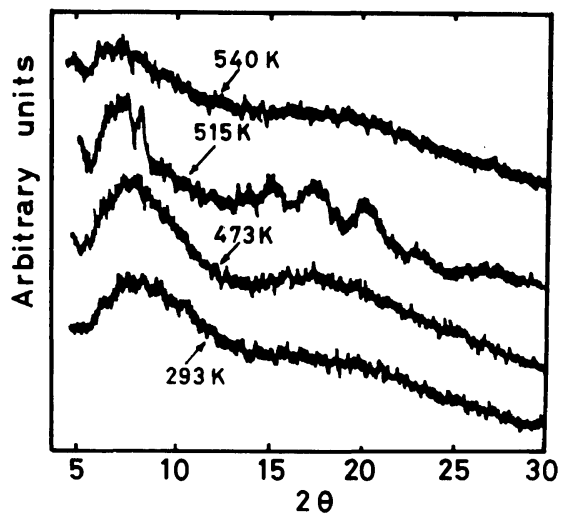

Figure 11. X-Ray diffractograms of the $\mathrm{CA}(2.46)$ fraction (EF3-14) at temperatures from 293 to $540 \mathrm{~K}$. Curve numbers denote temperature.

a $\mathrm{CA}(2.46)$ fraction $(\mathrm{EF} 3-14)$ at various temperatures. The diffraction curve at $293 \mathrm{~K}$ is almost the same as that of the CA(2.92) polymer at $293 \mathrm{~K}$, indicating the crystal form of CA(2.46) also to be CTA-II. In the temperature range from 293 to $473 \mathrm{~K}$, the diffraction intensity between $2 \theta=7.1$ and $17^{\circ}$ increased with an increase in temperature. The relation between DIR and temperature is illustrated by the broken line in Figure 6. DIR reached a maximum at about $490 \mathrm{~K}$. A small exothermic peak in DSC curve of $\mathrm{CA}(2.46)$ fractions with $M_{w}=1.08 \times 10^{5}$ and $1.85 \times 10^{5}$ at near $490 \mathrm{~K}$ resulted from crystallization. Above $490 \mathrm{~K}$, DIR decreased remarkably and in this temperature region, there was an endothermic peak in DSC curve of CA(2.46) fractions. In the diffractogram at $540 \mathrm{~K}$, there remained small peaks at 7.1 and $16^{\circ}$, and DIR at this temperature was 0.75 . The CA(2.46) fractions may have multiple melting points as in the case of some synthetic polymers, such as heat treated polypropylene $e^{28}$ and polyethylene. ${ }^{29}$ One melting point of the $\mathrm{CA}(2.46)$ fractions was about $500 \mathrm{~K}$ (we denote this point as $T_{\mathrm{m}}^{\prime}$ ). Other melting points were higher than $550 \mathrm{~K}$.

Following the same line of the above discussion on $\mathrm{CA}(2.92)$ and $\mathrm{CA}(2.46)$, we can speculate that the endothermic peak observed 


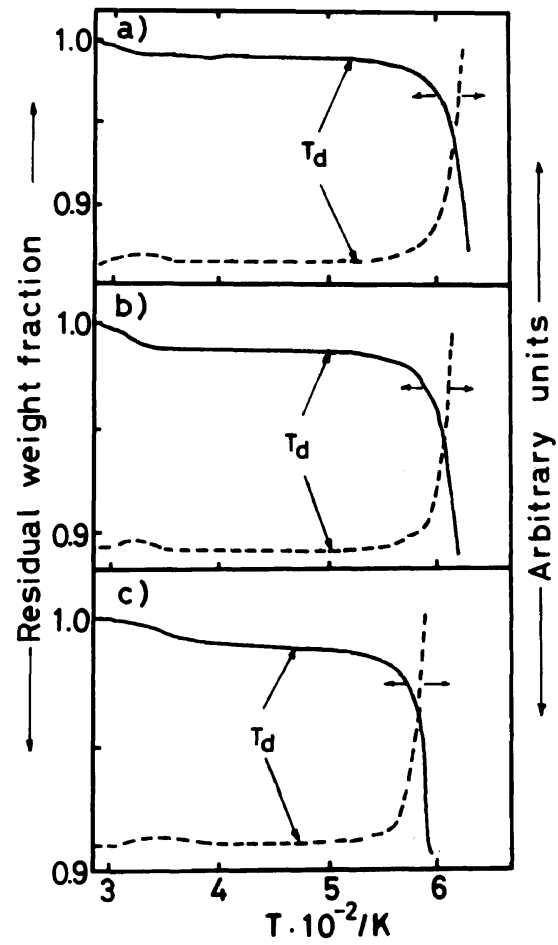

Figure 12. Thermogravimetry (TG) and differential thermogravimetry (DTG) curves of the CA(2.92) $\left(M_{w}=\right.$ $\left.1.49 \times 10^{5}\right), \operatorname{CA}(2.46)\left(M_{w}=1.41 \times 10^{5}\right)$ and $\mathrm{CA}(0.49)$ $\left(M_{w}=1.45 \times 10^{5}\right)$ fractions. Solid line, TG curve; broken line, DTG curve. $T_{\mathrm{d}}$, temperature at start of decomposition.

at $510-520 \mathrm{~K}$ in the DSC curve of CA(1.75) (Figure 8) corresponding to the melting point. Figures 7 and 8 suggest that $T_{\mathrm{m}}$ of the $\mathrm{CA}(2.46)$ and $\mathrm{CA}(1.75)$ fractions is almost independent of molecular weight.

Figure 12 depicts the TG and DTG curves of the $\mathrm{CA}(2.92), \mathrm{CA}(2.46)$, and $\mathrm{CA}(0.49)$ fractions. $T_{\mathrm{d}}$ of the $\mathrm{CA}(2.92), \mathrm{CA}(2.46)$, and $\mathrm{CA}(0.49)$ fractions determined from these curves was 524,508 , and $483 \mathrm{~K}$, respectively. $T_{\mathrm{d}}$ very slightly increased with increasing molecular weight and Figure 13 illustrates the case of the $\mathrm{CA}(2.46)$ fractions, where $\mathrm{d} T_{\mathrm{d}} / \mathrm{d} M_{w}$ was $8 \times 10^{-5} \mathrm{~K}$.

\section{Effects of $\langle F\rangle$ on $T_{\mathrm{g}}, T_{\mathrm{m}}$, and $T_{\mathrm{d}}$}

Figure 14 shows the plots of $T_{\mathrm{g}}$ and $T_{\mathrm{m}}$,

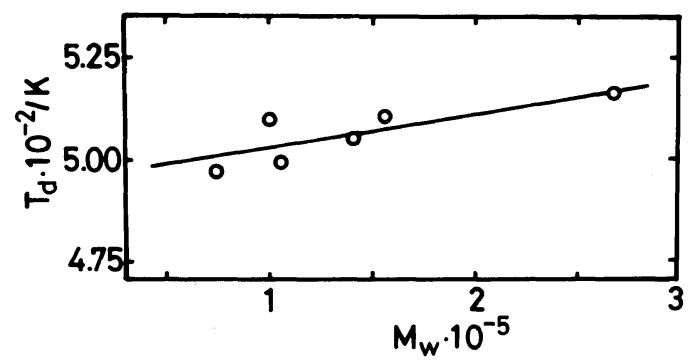

Figure 13. $T_{\mathrm{d}}$ of $\mathrm{CA}(2.46)$ fractions determined by $\mathrm{TG}$ as a function of weight-average molecular weight $M_{w}$.

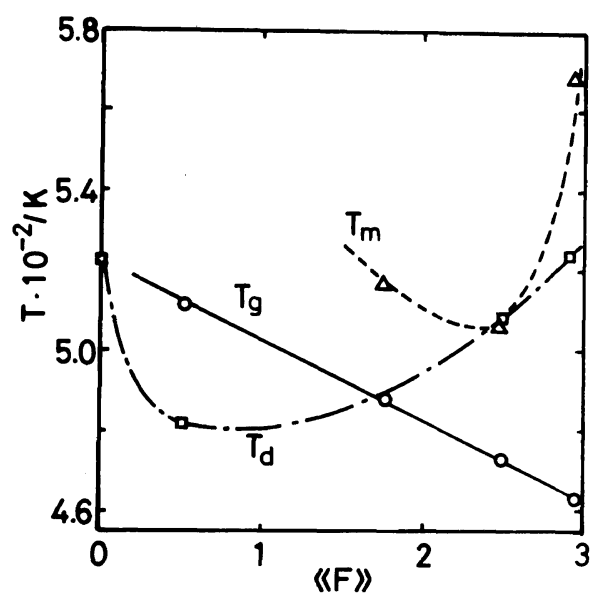

Figure 14. Total degree of substitution $\langle\mathrm{F}\rangle$ dependence of $T_{\mathrm{g}}, T_{\mathrm{m}}$, determined by DSC and $T_{\mathrm{d}}$ by TG. $\bigcirc$, $T_{\mathrm{g}} ; \triangle, T_{\mathrm{m}} ; \square, T_{\mathrm{d}}$. Solid line, $T_{\mathrm{g}}$; broken line $T_{\mathrm{m}}$; chain line, $T_{\mathrm{d}}$.

determined by DSC and $T_{\mathrm{d}}$ by TG as a function of $\langle\mid F\rangle$. Here, if the molecular weight dependence cannot be neglected, as in the case of $T_{\mathrm{g}}$ of CA(2.92), the value at $M_{v}=1 \times 10^{5} \mathrm{can}$ be employed. $T_{\mathrm{m}}^{\prime}$ was plotted as $T_{\mathrm{m}}$ of $\mathrm{CA}(2.46) . T_{\mathrm{d}}$ of regenerated cellulose (i.e., $T_{\mathrm{d}}$ at $\left\langle\langle\mathrm{F}\rangle=0\right.$ ) was measured by Kamide et al. ${ }^{30}$ by TG under the same conditions as those used here. $T_{\mathrm{g}}$ of CA increased almost linearly with a decrease in $\langle\langle F\rangle$ as follows

$$
T_{\mathrm{g}}(\mathrm{K})=523-20.3\langle\mathrm{~F} 》
$$

Recently, Kamide et al. $^{31}$ succeeded by the infrared absorption method in estimating separately the intra- and inter-molecular interactions between $\mathrm{O}$-acetyl and $\mathrm{OH}$ groups 
Thermal Analysis of Cellulose Acetates

Table II. $T_{\mathrm{g}}, T_{\mathrm{c}}, T_{\mathrm{m}}$, and $T_{\mathrm{d}}$ of cellulose acetates determined in this study

\begin{tabular}{|c|c|c|c|c|c|}
\hline \multirow{2}{*}{$\left\langle\langle F\rangle^{a}\right.$} & \multirow{2}{*}{$\begin{array}{c}\text { Fraction or } \\
\text { whole polymer }\end{array}$} & \multicolumn{4}{|c|}{ Thermal characteristic temp/K } \\
\hline & & $T_{\mathrm{g}}$ & $T_{\mathrm{c}}$ & $T_{\mathrm{m}}$ & $T_{\mathrm{d}}$ \\
\hline \multirow{2}{*}{2.92} & Fra $^{b}$ & $459-467$ & $482-492$ & 564,567 & 525 \\
\hline & $W^{c}$ & 460 & - & $\mathrm{nm}^{\mathrm{d}}$ & $\mathrm{nm}$ \\
\hline \multirow{2}{*}{2.46} & Fra & $473^{e}$ & 490 & $502-509$ & $497-516$ \\
\hline & WP & 480 & - & 500 & $\mathrm{~nm}$ \\
\hline \multirow{2}{*}{1.75} & Fra & $490^{e}$ & - & $513-519$ & $\mathrm{~nm}$ \\
\hline & WP & 489 & - & 514 & $\mathrm{~nm}$ \\
\hline \multirow{2}{*}{0.49} & Fra & $512^{\mathrm{e}}$ & - & - & 472 \\
\hline & WP & 520 & - & - & $\mathrm{nm}$ \\
\hline
\end{tabular}

a Total degree of substitution. ${ }^{b}$ Fraction. ${ }^{c}$ Whole polymer.

d Not measured. e Average value of all fractions.

and/or between $O$-acetyl or between $\mathrm{OH}$ groups for $\mathrm{CA}(2.92)$ and $\mathrm{CA}(2.46)$. $\langle\mathrm{F} \gg \mathrm{de}-$ pendence of $T_{\mathrm{g}}$ for CA fractions suggests the strength of the interaction between $O$-acetyl and $\mathrm{OH}$ groups or between $\mathrm{OH}$ groups to be stronger than that between $O$-acetyl groups. $T_{\mathrm{g}}$ of cellulose, as an asymptotic value obtained by extrapolating $T_{\mathrm{g}} v s$. $\langle\mathrm{F}\rangle$ curve to $\langle\langle\mathrm{F}\rangle=0$ was $523 \mathrm{~K}$. Manabe et al. ${ }^{32}$ measured some isochronal dynamic viscoelasticities of regenerated cellulose fiber at frequency of $110 \mathrm{~Hz}$, observing three absorption peaks at $298 \mathrm{~K}$ (they denoted as $\alpha_{\mathrm{H}_{2} \mathrm{O}}$ ), $513 \mathrm{~K}\left(\alpha_{2}\right), 573 \mathrm{~K}$ $\left(\alpha_{1}\right)$ and one shoulder at $393 \mathrm{~K}\left(\alpha_{\mathrm{sh}}\right)$. The $\alpha_{2}$ peak was due to the relaxation caused by microbrownian motion of the polymer molecules except for the tautly tied molecules in the amorphous region. ${ }^{32}$ The asymptotic $T_{\mathrm{g}}$ value at $\left\langle\langle\mathrm{F}\rangle=0\right.$ was close to $513 \mathrm{~K}$ of $\alpha_{2}$ peak.

$T_{\mathrm{m}}$ and $T_{\mathrm{d}}$ of CA became minimum at $\langle\mathrm{F}\rangle \simeq 2.5$ and $\simeq 1$, respectively. $\langle\mathrm{F}\rangle$ dependence of $T_{\mathrm{d}}$ suggests that the molecular interaction in CA solids influences the thermal degradation temperature.

In summary, the $T_{\mathrm{g}}, T_{\mathrm{c}}, T_{\mathrm{m}}$, and $T_{\mathrm{d}}$ values of the CA fractions and whole polymers with $\langle\mathrm{F}\rangle$ ranging from 0.49 to 2.92 , determined in this study are listed in Table II. The CA(2.92) and $\mathrm{CA}(2.46)$ fractions have $T_{\mathrm{g}}, T_{\mathrm{c}}$ (except some CA(2.46) fractions), $T_{\mathrm{m}}$ and $T_{\mathrm{d}}$. But in the case of the $\mathrm{CA}(2.92), \mathrm{CA}(2.46), \mathrm{CA}(1.75)$, and $\mathrm{CA}(0.49)$ whole polymers and all of $\mathrm{CA}(1.75)$ and $\mathrm{CA}(0.49)$ fractions $T_{\mathrm{c}}$ did not appear. The $\mathrm{CA}(0.49)$ polymer did not have $T_{\mathrm{m}}$, since $T_{\mathrm{d}}$ is far below its melting point. $T_{\mathrm{g}}$, $T_{\mathrm{m}}$, and $T_{\mathrm{d}}$ depend on $\langle\mathrm{F}\rangle$ significantly, but are almost independent of average-molecular weight, except for $T_{\mathrm{g}}$ of the $\mathrm{CA}(2.92)$ fractions.

Acknowledgements. The authors express their sincere gratitude to Mr. T. Okino of Kyoto Analytical Application Lab. of Shimadzu Co., Ltd. (Kyoto), for his technical assistance and helpful advice in the TG measurements.

\section{REFERENCES}

1. K. Ueberreiter, Z. Phys. Chem., B48, 197 (1941).

2. J. M. Cowie and R. J. Ranson, Makromol. Chem., 143, 105 (1971).

3. S. Nakamura, S. Shindo, and K. Matuzaki, J. Polym. Sci., Polym. Lett. Ed., 9, 591 (1971).

4. A. Arneri and J. A. Sauer, Thermochim. Acta, 15, 29 (1976).

5. H. Trivedi, K. C. Patel, and R. D. Patel, J. Macromol. Sci., Chem. Ed., A19, 851 (1983).

6. K. S. Patel, K. C. Patel, and R. D. Patel, Makromol. Chem., 132, 7 (1970).

7. A. Scotney, Eur. Polym. J., 8, 163 (1972).

8. R. K. Jain, K. Lal, and H. L. Bhatnager, Makromol. Chem., 183, 3003 (1982).

9. F. E. Willey, Ind. Eng. Chem., 34, 1052 (1942). 
10. R. F. Clash and L. M. Rynkiewicz, Ind. Eng. Chem., 36, 279 (1944).

11. L. Manderkern and P. J. Flory, J. Am. Chem. Soc., 73, 3206 (1951).

12. K. Nakamura, Kobunshi Kagaku, 13, 47 (1956).

13. J. Russel and R. G. Kerpel, J. Polym. Sci., 25, 77 (1957).

14. A. Sharple and F. L. Swinton, J. Polym. Sci., 50, 53 (1961).

15. J. H. Daane and R. E. Barker, J. Polym. Sci., Polym. Lett. Ed., 2, 343 (1964).

16. K. Kamide, Y. Miyazaki, and T. Abe, Polym. J., 11, 523 (1979).

17. K. Kamide, T. Terakawa, and Y. Miyazaki, Polym. J., 11, 285 (1979).

18. K. Kamide, M. Saito, and T. Abe, Polym. J., 13, 421 (1981).

19. K. Kamide and M. Saito, Polym. J., 14, 517 (1982).

20. M. Saito, Polym. J., 15, 249 (1983).

21. K. Kamide and K. Okajima, Polym. J., 13, 127 (1981).

22. K. Kamide, K. Kagawa, and S. Manabe, Netsu Sokutei, 4, 7 (1977).
23. J. M. Cowie and S. A. E. Henshall, Eur. Polym. J., 12, 215 (1976).

24. See, for example, J. Blackwell and R. H. Marchessault, "Cellulose and Cellulose Derivatives," Part IV, N. M. Bikales and L. Segel, Ed., WileyInterscience, New York, N. Y., 1971, p 19, Chapter 13.

25. B. S. Sprague, J. L. Riley, and H. D. Noether, Text. Res. J., 28, 275 (1958).

26. J. J. Creely and C. M. Conrad, Text. Res. J., 32, 184 (1966).

27. R. F. Schwenker and L. R. Beck, Text. Res. J., 30, 624 (1960).

28. K. Kamide and M. Sanada, Kobunshi Kagaku, 24, 662 (1967).

29. T. Kawai, M. Hosoi, and K. Kamide, Makromol. Chem., 146, 55 (1971).

30. K. Kamide, K. Okajima, and K. Uchida, unpublished results.

31. K. Kamide, K. Okajima, and M. Saito, Polym. J., 13, 115 (1981).

32. S. Manabe, Y. Komatsu, M. Iwata, and K. Kamide, unpublished results. 